\title{
Influence of glass-fiber reinforcement on the flexural strength of different resin composites
}

\author{
Rodrigo Vieira Caixeta, Ricardo Danil Guiraldo*, Sandrine Bittencourt Berger, Edmilson Nobumitu Kaneshima, \\ Élcio Mário Faria Júnior, Amauri Cruz Drumond, Alcides Gonini Júnior and Murilo Baena Lopes
}

${ }^{*}$ Correspondence:

rdguiraldo@gmail.com

University of North Parana,

Rua Marselha, 183, Londrina,

PA CEP 86041-100, Brazil

\section{Springer}

\begin{abstract}
Fiber-reinforced composites have recently been advocated as an alternative to fixed metal framework prostheses. The aim of this study was to evaluate the effect of glassfiber reinforcement on the flexural strength of different resin composites. The tested composites were X-tra fil, Filtek Z350 XT Flow and Filtek Z350 XT commercially available and reinforced with glass-fiber. Six groups of bars specimens $(2 \times 2 \times 20 \mathrm{~mm})$ were prepared $(n=10)$. The measurement of flexural strength of the resin composites was carried out by the three-point bending test. Data were subjected to ANOVA and post hoc Tukey's tests $(a=0.05)$. The flexural strength of all composites was improved when combined with glass fiber. The bulk-fill X-tra fil composite (133.53 MPa) was the strongest fiber-reinforced material. Clinically, fiber reinforcement should be employed in extensive restorations to provide increased flexural strength.
\end{abstract}

Keywords: Composites, Glass fiber, Structural reinforcement, Flexural strength

\section{Background}

Due to the enormous demand for conservative and aesthetic restorations [1], fiber-reinforced composites (FRC) have recently been advocated as an alternative to fixed metal framework prostheses. Compared to metal prostheses, FRC restorations are lighter and more esthetic [1]. In addition, the restorations can be effectively adhered to dental tissues and cause less damage to remaining teeth [2]. Although the durability of this type of prosthesis is inferior to metal frameworks, much less time and cost are associated to its placement [2]. FRC's durability has been reported differently in the related studies, so that the overall durability rate of 75-94.75 percent has been reported after three to 5 years $[1,3-5]$.

The use of composite materials in metal-free fixed partial dentures (FPDs) became feasible following the introduction of fiber reinforcement [6]. FRC-based FPDs have good resistance to masticatory forces [6] in addition to their low cost, improved aesthetics, reduced weight, and favorable elastic modulus [7, 8]. Prosthetics manufactured from ceramic material have superior color stability and wear resistance, exhibit marginal adhesion to tooth structure, and have the potential to damage unrestored opposing teeth [9]. FRC materials are currently used not only for crowns and inlays, but also

(c) 2015 Caixeta et al. This article is distributed under the terms of the Creative Commons Attribution 4.0 International License (http://creativecommons.org/licenses/by/4.0/), which permits unrestricted use, distribution, and reproduction in any medium, provided you give appropriate credit to the original author(s) and the source, provide a link to the Creative Commons license, and indicate if changes were made. 
for a variety of clinical esthetic restorations, for example the infrastructure of implantsupported crowns and for FPDs [10]. Although several fiber materials are commercially available, polyethylene and glass fiber reinforcing materials are the most popular [6]. Silanized glass fibers provide good adhesion to the polymer matrix, good aesthetic quality, and improved strength of the resulting composite $[8,11]$. The study has have examined the effects of variables such as position, quantity, fiber orientation, and degree of adhesion between the fibers and polymer on the level of reinforcement [12].

FRC materials can adapt to dental contours and are easily manipulated during the bonding process. The materials also possess acceptable strength and clinical durability due to the integration of the fibers with the composite resin and the potential for attachment closer to the incisal edges of teeth, which is useful from a biomechanical perspective $[13,14]$. Problems with porcelain-fused-to-metal FPDs include poor aesthetics due to the exposed metal margin and harmful effects on periodontal tissues from the release of metal ions [9]. The increasing application of metal-free FPDs made using ceramic [15] or resin materials [16] is primarily due to advances in high-strength particulate composite resins [17], improved adhesion techniques [18], and the development of highstrength fiber-reinforced composites [19].

The aim of this study was to evaluate the effect of glass-fiber reinforcement on the flexural strength of different resin composites. The null hypotheses tested were (1) that there is no difference in flexural strength among specimens made with different resin composites (bulk-fill, flow, and conventional resin composites), and (2) glass fiber reinforcement has no effect on flexural strength.

\section{Methods}

\section{Specimen preparation}

Details of the materials used in this study are provided in Table 1. A total of 60 barshaped specimens in six groups $(\mathrm{n}=10)$ were prepared in a metal mold $(2 \times 2 \times 20 \mathrm{~mm})$. The samples were prepared using the conventional nanoparticle-filled composite Filtek Z350 XT (batch number 775639; 3M ESPE, St. Paul, MN, USA), Filtek Z350 XT Flow composite (batch number N509855; 3M ESPE), or the bulk-fill X-tra fil composite (batch number 1315355; Voco, Cuxhaven, Germany).

The materials were placed in the metal mold in a single portion. Sets of 10 specimens of each composite were prepared neat and with pre-impregnated glass fiber

Table 1 Materials used in the study

\begin{tabular}{|c|c|c|}
\hline Materials & Manufacturer/batch number & Chemical composition (weight \%) \\
\hline Interlig & Angelus, Londrina, PR, Brazil/31464 & $\begin{array}{l}\text { Glass fibers }-60 \pm 5 \% \\
\text { Impregnated with } 40 \pm 5 \% \text { resin containing } \\
\text { Bis-GMA, diurethane, barium glass }\end{array}$ \\
\hline X-tra fil & Voco, Cuxhaven, Germany/1315355 & Inorganic filler-86 \%: Bis-GMA, UDMA, TEDMA \\
\hline Filtek Z350 XT Flow & 3M ESPE, St. Paul, MN, USA/N509855 & $\begin{array}{l}\text { Inorganic filler-65 \%: Bis-GMA, TEGDMA, Bis- } \\
\text { EMA }\end{array}$ \\
\hline Filtek Z350 XT universal & 3M ESPE, St. Paul, MN, USA/775639 & $\begin{array}{l}\text { Inorganic filler-78,5 \%: Bis-GMA, Bis-EMA, } \\
\text { UDMA, TEGDMA }\end{array}$ \\
\hline
\end{tabular}

Bis-GMA bisphenylglycidyl dimethacrylate, BisEMA ethoxylated bisphenol-A dimethacrylate, TEGDMA triethylene glycol dimethacrylate, UDMA urethane dimethacrylate 
reinforcement (batch number 31464; Interlig, Angelus, Londrina, PR, Brazil). The composites were photoactivated with a 40 -second exposure $\left(940 \mathrm{~mW} / \mathrm{cm}^{2}\right)$ in three areas (extreme right, center, and extreme left) of the metal mold (top surfasse) using an LED lamp (Radii Cal; SDI, Bayswater, VIC, Australia). Following photoactivation, the specimens were stored dry at $37^{\circ} \mathrm{C}$ for $24 \mathrm{~h}$. The specimen surfaces were ground using 200-, 400-, and 600-grit SiC abrasive (Carborundum; Saint-Gobain Abrasives, Recife, PE, Brazil) to obtain polished, flat surfaces. The specimen dimensions were measured using a digital caliper (model CD-15C; Mitutoyo, Tokyo, Japan). All procedures were performed by a single operator to ensure standardization.

\section{Flexural strength test}

A three-point bending flexural test was performed on each specimen using a universal testing machine (DL2000, EMIC, Equipamentos e Sistemas de Ensaio LTDA, São José dos Pinhais, PR, Brazil). The load was applied perpendicular to the long axis of the specimen at a crosshead speed of $0.5 \mathrm{~mm} / \mathrm{min}$ until fracture. The flexural strength (FS [MPa]) was calculated using the equation $\mathrm{FS}=3 \mathrm{~F}_{\max } \mathrm{L} / 2 \mathrm{WH}^{2}$ [20], in which $\mathrm{F}_{\max }$ is the maximum load in newtons, $\mathrm{L}$ is the distance between the support points $(8 \mathrm{~mm})$, and $\mathrm{W}$ and $\mathrm{H}$ are the specimen width and thickness in $\mathrm{mm}$.

\section{Statistical analysis}

Mean values and standard deviations (SDs) for flexural strength measurements were calculated using the Minitab 16 program for Windows 8 (Minitab, State College, PA, USA). Normality of the data distributions was investigated using the Kolmogorov-Smirnov normality test. Results were compared using two-way analysis of variance (ANOVA, variables composite and fiber reinforcement) and Tukey's test at a $5 \%$ significance level $(\alpha=0.05)$.

\section{Results}

Addition of glass fiber increased the flexural strength of all composites (Table 2, $\mathrm{p}=0.013)$. The X-tra fil (102.86 MPa) and Filtek Z350 XT (101.51 MPa) composites without glass fiber had similar flexural performance, however, the X-tra fil composite experienced greater improvement when blended with glass fiber (133.53 MPa). The flexural strength of the Z350 XT Flow composite was also improved by addition of glass fiber, but the performance of this material was lower than the other two composites.

Table 2 Mean flexural strength (MPa) for composites with and without fiber reinforcement with respective standard deviations

\begin{tabular}{llr}
\hline Composite & \multicolumn{1}{l}{ Flexural strength (MPa) } & \\
\cline { 2 - 3 } & Fiber & Without fiber \\
\hline X-tra fil & $133.53(8.80) \mathrm{Aa}$ & $102.86(6.39) \mathrm{Ab}$ \\
Filtek Z350 XT & $116.14(6.62) \mathrm{Ba}$ & $101.51(6.66) \mathrm{Ab}$ \\
Filtek Z350 XT Flow & $104.29(9.05) \mathrm{Ca}$ & $82.70(9.20) \mathrm{Bb}$ \\
\hline
\end{tabular}

Mean values followed by different uppercase letters in columns and lowercase letters in rows differed statistically in Tukey's test at $5 \%(p=0.013)$. Standard deviations are in parentheses 


\section{Discussion}

Flexural strength and modulus of elasticity are the two most important mechanical characteristics in the evaluation of the fiber reinforcement systems [1]. The three-point bending test is a simple method used for comparison of the load bearing capacity of different unidirectional FRC beams [21]. The flexural strength, which is measured in the three-point bending test, determines the behavior of the material under simultaneous tensile and compressive loading $[1,2]$.

FRC has been used in a variety of dental applications, including denture bases and posts for root canal treatment [22], but it has only recently been used for FPDs [9]. Inlay-retained FPDs reinforced with FRC have a reported survival rate of $72-75 \%$ at 36-63 months after treatment [5]. It has also been noted [5] that the functional survival rate can be improved to $93 \%$ by repair or reinstallation, because the cause of failure in most cases is attributable to dislodgment or partial fracture. From the above discussion, it may be inferred that fiber reinforcement is effective, but a sufficient thickness of veneering composite must be applied to the connector area to prevent fractures [9].

Glass used for the fabrication of such fibers is an amorphous tetrahydrosilicate-based material [1], and the chemical and physical characteristics are distinctly different from organic fibers [1]. Improved adhesion of composites and glass fibers could be due to the sílica contents of the fiber and consequent stronger bonds which in turn lead to an increased flexural strength [23]. Another reason for the high flexural strength of the glass fiber and composites resin combination could be the strongest chemical bond between the glass fiber and the dental polymers [1]. X-tra fil, a bulk fill composite, contains BisGMA, UDMA, and TEDMA with 86 wt \% filler particules, while Z350 XT contains BisGMA, Bis-EMA, UDMA, TEGDMA with 78.5 wt \% filler particles and Filtek Z350 XT Flow contains Bis-GMA, TEGDMA, Bis-EMA with 65 wt \% filler particles. Moreover, the combination composite with glass fiber presented greater flexural strength than glass fiber alone [1].

One approach to increase the adhesion of fibers to a polymer matrix is resin impregnation of fibers before application [12]. An effective impregnation process enables the resin to come into contact with the surface of every fiber [12]. Wetting the fibers with resin monomer has been a commonly used method. However, although the monomer increases the adhesion of fibers to the matrix, residual monomer may impair other properties [12]. The pre-impregnated fiber used in the present study was developed to overcome this problem [12]. Investigators have confirmed the reinforcing effect of fibers on different polymer types $[11,24,25]$. The increase in flexural strength results from the transfer of stress from the weak polymer matrix to the fibers, which have a high tensile strength [24]. The stronger the adhesion between the fiber and the matrix, the greater the strengthening effect [25]. In composites containing both reinforcing fiber and particulate fillers, the interfacial adhesion and matching of flexural modulus of these two phases plays an important role in increasing the mechanical properties of the material, and further research should be conducted to improve the interfacial bond strength [19].

Reinforcing composites with polyethylene fibers can yield enhanced mechanical properties [26] such as stiffness, strength, toughness, and fatigue resistance [27]. Fibers provide a load-enhancing effect in brittle resin materials by acting as a stress-bearing component and by crack-stopping or crack-deflecting mechanisms [26]. Fixed 
fiber-reinforced composite bridges offer a suitable alternative to replace missing permanent anterior teeth, particularly in growing children until a fixed prosthesis can be provided at the end of the growth period [28]. Methodologically, limitations such as sample size and aging processes (alternating thermal stresses, mechanical stresses, wear and water storage) should be taken into consideration. Despite the importance of laboratory studies to answer some questions over the short term, the real performance of restorations can only be determined by long-term clinical trials [29].

In specimens in which fiber reinforcement was not used, there were no differences in flexural strength between X-tra fil and Filtek Z350 XT composite. Filtek Z350 XT exhibited high flexural strength despite an inhomogeneous distribution of filler particles [20, 30], while X-tra fil inherently contained a greater proportion of fillers. Filtek Z350 XT Flow demonstrated lower flexural strength, probably due to a lower filler content. However, when other tests were performed (such as the push-out test) the results were not the same [31]. Thus, future studies are needed to demonstrate the efficacy of bulk-fill composites that performed well during flexural testing in this study. The null hypotheses discussed earlier must be rejected because (1) there were differences in flexural strength among specimens prepared from different resin composites, and (2) addition of glass fiber affected the strength of the resulting composite.

\section{Conclusions}

Analysis of the flexural strength indicates that glass fiber reinforcement improved the performance of any of the three composites tested. Fiber reinforcement showed highest flexural strength with the bulk-fill composite, while the lowest flexural strength was observed for the flowable composite.

Authors' contributions

RVC, SBB, ENK and AGJ participated in performing the experiments. EMFJ and MBL contributed to the writing of the manuscript. ACD performed the statistical analysis. RDG conceived of the study, participating in its design and coordination, helping to drafting the manuscript. All authors read and approved the final manuscript.

\section{Competing interests}

The authors declare that they have no competing interests.

Received: 15 November 2015 Accepted: 13 December 2015

Published online: 21 December 2015

References

1. Sharafeddin F, Alavi AA, Talei Z. Flexural strength of glass and polyethylene fiber combined with three different composites. J Dent Shir. 2013;14(1):13-9.

2. Pereira CL, Demarco FF, Cenci MS, Osinaga PW, Piovesan EM. Flexural strength of composites: influences of polyethylene fiber reinforcement and type of composite. Clin Oral Investig. 2003;7(2):116-9.

3. Heumen CC, Dijken JW, Tanner J, Pikaar R, Lassila LV, Creugers NH, Vallittu PK, Kreulen CM. Five-year survival of 3-unit fiber-reinforced composite fixed partial dentures in the anterior area. Dent Mater. 2009;25(6):820-7.

4. Piovesan EM, Demarco FF, Piva E. Fiber-reinforced fixed partial dentures: a preliminary retrospective clinical study. J Appl Oral Sci. 2006;14(2):100-4.

5. Vallittu PK. Survival rates of resin-bonded, glass fiber-reinforced composite fixed partial dentures with a mean follow-up of 42 months: a pilot study. J Prost Dent. 2004;91(3):241-6.

6. Tabatabaei $\mathrm{MH}$, Hasani Z, Ahmadi E. In vitro evaluation of veneering composites and fibers on the color of fiberreinforced composite restorations. J Dent. 2014;11(4):473-80.

7. Van Heumen CC, Kreulen CM, Creugers NH. Clinical studies of fiber-reinforced resin-bonded fixed partial dentures: a systematic review. J Oral Sci. 2009;117(1):1-6.

8. Kolbeck C, Rosentritt M, Behr M, Lang R, Handel G. In vitro study of fracture strength and marginal adaptation of polyethylene- fi-ber-reinforced-composite versus glass-fibre-reinforced-composite fixed partial dentures. J Oral Rehabil. 2002;29(7):668-74. 
9. Waki T, Nakamura T, Nakamura T, Kinuta S, Wakabayashi K, Yatani H. Fracture resistance of inlay-retained fixed partial dentures reinforced with fiber-reinforced composite. Dent Mater J. 2006;25(1):1-6.

10. Tanoue N, Sawase T, Matsumura H, McCabe JF. Properties of indirect composites reinforced with monomer-impregnated glass fiber. Odontology. 2012;100(2):192-8.

11. Hamza TA, Rosenstiel SF, El-Hosary MM, Ibraheem RM. Fracture resistance of fiber-reinforced PMMA interim fixed partial dentures. J Prosthodont. 2006;15(4):223-8.

12. Duymus ZY, Karaalioglu FO, Suleyman F. Flexural strength of provisional crown and fixed partial denture resins both with and without reinforced fiber. J Mater Sci Nanotechnol. 2014;2(1):102. doi:10.15744/2348-9812.1.302.

13. Karaman Al, Kir N, Belli S. Four applications of reinforced polyethylene fiber material in orthodontic practice. Am J Orthod Dentofac Orthop. 2002;121(6):650-4.

14. Jahanbin A, Abtahi M, Heravi F, Hoseini M, Shafaee H. Analysis of different positions of fiber-reinforced composite retainers versus multistrand wire retainers using the finite element. Int J Biomater. 2014;2014:581029. doi:10.1155/2014/581029.

15. Olsson KG, Furst B, Andersson B, Carlsson GE. A long-term retrospective and clinical follow-up study of In-Ceram Alumina FPDs. Int J Prosthodont. 2003;16(2):150-6.

16. Vallittu PK, Sevelius C. Resin-bonded, glass fiberreinforced composite fixed partial dentures: a clinical study. J Prosthet Dent. 2000;84(8):413-8.

17. Mandikos MN, McGivney GP, Davis E, Bush PJ, Carter JM. A comparison of the wear resistance and hardness of indirect composite resins. J Prosthet Dent. 2001;85(4):386-95.

18. Shimura R, Nikaido T, Yamauti M, Ikeda M, Tagami J. Influence of curing method and storage condition on microhardness of dual-cure resin cements. Dental Mater J. 2005;24(1):70-5.

19. Bae JM, Kim KN, Hattori M, Hasegawa K, Yoshinari M, Kawada E, Oda Y. Fatigue strengths of particulate filler composites reinforced with fibers. Dent Mater J. 2004;23(2):166-74.

20. Lopes MB, Serralvo AD, Felizardo KR, Hirata BS, Guiraldo RD, Berger SB, Borges AH, Gonini-Júnior A. Evaluation of the flexural resistance and stress contraction of a silorane-based composite submitted to different protocols of polymerization. Appl Adhes Sci. 2014;2:23.

21. Behr M, Rosentritt M, Leibrock A, Schmeider-Feyrer S, Handel G. In vitro study of fracture strength and marginal adaptation of fiber-reinforced adhesive fixed partial inlay dentures. J Dent. 1999;27(2):163-8.

22. Kanie T, Arikawa H, Fujii K, Ban S. Light-curing reinforcement for denture base resin using a glass fiber cloth preimpregnated with various urethane oligomers. Dent Mater J. 2004;23(3):291-6.

23. Hammouda IM. Reinforcement of conventional glassionomer restorative material with short glass fibers. J Mech Behav Biomed Mater. 2009;2(1):73-81. doi:10.1016/j.jmbbm.2008.04.002.

24. Nohrstrom T, Vallittu P, Yli-Urpo A. The effect of placement and quantity of glass fibers on the fracture resistance of interim fixed partial dentures. Int J Prosthodont. 2000;13(1):72-8.

25. Solnit GS. The effect of methyl methacrylate reinforcements with silane treated and untreated glass fibers. J Prosthet Dent. 1991;66(3):310-4.

26. Issac DH. Engineering aspects of the structure and properties of polymer-fibre composites. In: Proceedings of the first symposium on fiber reinforced plastic in dentistry, 1998;1-21.

27. Ramakrishna Y, Munshi AK. Fiber reinforced composite loop space maintainer: an alternative to the conventional band and loop. Contemp Clin Dent. 2012;3(5):26-8.

28. Gupta A, Yelluri RK, Munshi AK. Fiber-reinforced composite resin bridge: a treatment option in children. Int J Clin Pediatr Dent. 2015;8(1):62-5.

29. Garoushi S, Mangoush E, Vallittu P, Lassila L. Short fiber reinforced composite: a new alternative for direct onlay restorations. Open Dent J. 2013;7:181-5. doi:10.2174/1874210601307010181.

30. Palin WM, Fleming GJ, Burke FJ, Marquis PM, Randall RC. The influence of short and medium-term water immersion on the hydrolytic stability of novel low-shrink dental composites. Dent Mater. 2005;21(9):852-63. doi:10.1016/j. dental.2005.01.004.

31. Caixeta RV, Guiraldo RD, Kaneshima EN, Barbosa AS, Picolotto CP, Lima AE, Gonini Júnior A, Berger SB. Push-out bond strength of restorations with bulk-fill, flow, and conventional resin composites. ScientificWorldJournal. 2015;2015:452976. doi:10.1155/2015/452976.

\section{Submit your manuscript to a SpringerOpen ${ }^{\circ}$ journal and benefit from:}

- Convenient online submission

- Rigorous peer review

- Immediate publication on acceptance

- Open access: articles freely available online

- High visibility within the field

- Retaining the copyright to your article

Submit your next manuscript at $\boldsymbol{\nabla}$ springeropen.com 